\title{
PI3K-delta Inhibitor HMPL 689
}

National Cancer Institute

\section{Source}

National Cancer Institute. PI3K-delta Inhibitor HMPL 689. NCI Thesaurus. Code C148532.

An orally bioavailable selective inhibitor of the delta isoform of phosphatidylinositide 3kinase (phosphoinositide 3'-kinase delta; PI3Kd; PI3K-d), with potential antineoplastic activity. Upon oral administration, PI3K-delta inhibitor HMPL 689 selectively binds to and inhibits PI3Kd, and prevents the activation of the PI3Kd/AKT signaling pathway, and B-cell activation. This both decreases proliferation and induces cell death in PI3Kdoverexpressing tumor cells. PI3Kd plays a key role in the B-cell receptor (BCR) signaling pathway and the proliferation of hematologic cancer cells. The targeted inhibition of PI3Kd is designed to preserve PI3K signaling in normal, non-neoplastic cells and thereby to minimize serious side effects. PI3Kd, an enzyme often overexpressed in cancer cells, plays a crucial role in tumor cell regulation and survival. 